OPEN ACCESS

Edited by:

Michael P. Hengartner, Zurich University of Applied

Sciences, Switzerland

Reviewed by:

Lin Sørensen

University of Bergen, Norway

Maj-Britt Posserud,

Haukeland University

Hospital, Norway

*Correspondence:

Raz Gross

razgross@gmail.com

Specialty section:

This article was submitted to Child and Adolescent Psychiatry,

a section of the journal

Frontiers in Psychiatry

Received: 26 April 2020

Accepted: 08 October 2020

Published: 23 November 2020

Citation:

Kapra O, Rotem $R$ and Gross $R$ (2020) The Association Between Prenatal Exposure to Antidepressants and Autism: Some Research and

Public Health Aspects.

Front. Psychiatry 11:555740.

doi: 10.3389/fpsyt.2020.555740

\section{The Association Between Prenatal Exposure to Antidepressants and Autism: Some Research and Public Health Aspects}

\author{
Ori Kapra ${ }^{1}$, Ran Rotem ${ }^{2,3}$ and Raz Gross ${ }^{1,4,5 *}$ \\ ${ }^{1}$ Department of Epidemiology and Preventive Medicine, Sackler Faculty of Medicine, School of Public Health, Tel Aviv \\ University, Tel-Aviv, Israel, ${ }^{2}$ School of Public Health, Harvard University, Boston, MA, United States, ${ }^{3}$ Morris Kahn Maccabi \\ Health Data Science Institute, Tel-Aviv, Israel, ${ }^{4}$ Sheba Medical Center, Ramat Gan, Israel, ${ }^{5}$ Department of Psychiatry, Sackler \\ Faculty of Medicine, Sackler School of Medicine, Tel Aviv University, Tel Aviv, Israel
}

Use of antidepressants (ADs) in general, and in pregnant notwithstanding, has been increasing globally in recent decades. Associations with a wide range of adverse perinatal and childhood outcomes following prenatal ADs exposure have been observed in registry-based studies, with Autism Spectrum Disorders (ASD) frequently reported. Studies using animal models, sibling analyses, and negative control approaches, have linked dysfunctional serotonin metabolism with ASD, but did not convincingly tease apart the role of maternal mental health from that of ADs. As work to decipher the nature of the AD-ASD association continues, this review raises some public health concerns pertinent to a hypothetical conclusion that this association is causal, including the need to identify specific gestation periods with higher risk, the importance of precise assessment of the ASD potential prevention that might be attributed to AD discontinuation, and the estimation of risks associated with prenatal exposure to untreated depression.

Keywords: autism (ASD), antidepressant (AD), SSRI (selective serotonin reuptake inhibitor), prenatal, maternal depression, confounding by indication, in utero development

\section{INTRODUCTION}

Use of antidepressants (ADs) in pregnancy results in fetal exposure to the medications, in concentrations that are $70-80 \%$ of maternal serum levels (1). Yet, fetal exposure to ADs has not received the same clinical, ethical, or sociological attention that ADs use in children and adolescents has. From an ethical and public health research perspective, this topic introduces some key issues. First, unlike children and adolescents who are generally treated following the medical principle of primum non nocere ("First do not harm"), i.e., treating only those who have demonstrated sufficient impairment such that the benefits of treatment outweigh potential harm by adverse effects, fetuses are "innocent bystanders," passively exposed to AD. This is evident in studies suggesting the use of selective serotonin reuptake inhibitors (SSRIs), a class of $\mathrm{AD}$, has been increasing 
globally for the last 20-30 years, particularly among women and during pregnancy (2-8). Second, the choices facing physicians and pregnant women who struggle with mental health problems are complex, since in a dissimilarity to other exposures such as tobacco or illicit drugs where the goal is to eliminate use in pregnancy entirely, discontinuing the use of SSRIs and leaving maternal depression untreated may by itself have deleterious consequences for both mother and child (9-11). Hence, somewhat unique to investigations of prenatal exposure to $\mathrm{AD}$, and SSRIs in particular, is an epidemiological equivocality on whether one should look for the Number Needed to Harm $(\mathrm{NNH})$ or the Number Needed to Treat (NNT). Over the last decade, this conceptual ambiguity has not deterred the establishing of a consistent association with another public health concern, namely autism spectrum disorder (ASD) $(12,13)$.

\section{THE ASSOCIATION BETWEEN PRENATAL SSRIS AND AUTISM SPECTRUM DISORDER (ASD)}

Twin studies have proposed that up to $70 \%$ of monozygotic pairs are concordant for autism, while up to $\sim 90 \%$ are concordant for a broader spectrum of related cognitive or social abnormalities $(14,15)$. These heritability figures suggest that ASD is largely genetic, while providing substantial evidence that nonheritable factors are also likely to have an etiological role (16). Frequently mentioned among such prenatal exposures is use of SSRIs medications.

Fetal exposure to SSRIs is suspected as having significant consequences, mainly because well-before it assumes its renowned role as a neurotransmitter in adulthood, serotonin (5-HT) serves as a neural growth factor in gestation, critically influencing the brain structure and function of the developing fetus (17-22). All SSRIs cross the placenta, and while the mechanism by which SSRIs can potentially become hazardous during gestation is not entirely clear, associations with a wide range of adverse perinatal problems have been observed, including reduced fetal head growth (23), low birth weight (24), neural tube defects $(25,26)$, cardiac malformations (27), specifically atrial and ventricular defects (28), craniosynostosis (28), persistent pulmonary hypertension $(29,30)$, and lower APGAR scores (31).

Among childhood neuropsychiatric disorders, ASD has been associated with prenatal SSRIs exposure (32). Figure 1 shows that over the last decade observational studies have formed an aggregate of positive findings, with little, if any variety in their effect estimates (33-49). One meta analysis suggested a pooled odds ratio of 1.82 , with a $95 \%$ Confidence Interval $(\mathrm{CI})=1.59$ 2.10 (32) when comparing exposed and unexposed fetuses, or an adjusted odds ratio of 1.81 (95\% CI $=1.47-2.24)$ with nonsignificant heterogeneity of the effect estimates across studies (respectively: $Q=3.61, P=0.73 ; Q=0.5, P=0.92$ ) (45). Only a single meta-analysis to date produced null findings for the ASDSSRI association (adjusted RR $=1.13,95 \% \mathrm{CI}=0.93-1.39$ ) (50). This null finding has been interpreted by the authors as a failure of other meta-analyses to account for publication bias. The latest systematic review and meta-analysis comprising of 20 studies had calculated positive pooled Hazard Ratios (HR) for both cohort and case-control designs (respectively: $\mathrm{HR}=1.27,95 \%$ $\mathrm{CI}=1.10-1.47 ; \mathrm{HR}=1.60,95 \% \mathrm{CI}=1.26-2.02$ ), and similarly drew attention that a publication bias cannot be precluded from influencing the results (40). Still, the observed association between SSRIs and developmental disorders is currently hardly in contention. The possible causality implied by it, however, is debatable.

Several investigative strategies to assess the causality of the association between maternal $\mathrm{AD}$ use during pregnancy and ASD risk in progeny have emerged. Results from studies using animal models have strengthened hypothesis that early SSRIs exposure may alter normal brain development, hippocampal neurogenesis, and epigenetic programming (51-55). In humans, epidemiological samples have been studied by means of diverse analytic approaches, each presenting unique challenges. Regression models adjusted for maternal mental illness are limited due to established underreporting of depression (30, 56-60), which leads to incomplete control for confounding by indication or by depression severity, with the latter potentially also confounding the dose-response gradient between SSRI exposure and risk of ASD. Confining the analysis only to children born to mothers with a history of psychiatric disorders indeed seems to attenuate or nullify the SSRI-ASD association (3), as observed in one systematic review (46) and one meta-analysis (39) (respectively: pooled adjusted risk ratio $=1.18,9 \% \% \mathrm{CI}=0.91-1.52$; pooled odds ratio $=0.96,95 \%$ $\mathrm{CI}=0.57-1.6)$.

Figure 1 also shows studies demonstrating an association between maternal affective disorders and ASD, unconditioned on SSRIs use. The first and only meta-analysis to pool data on mothers with only psychiatric disorders but no SSRI exposure and those with SSRI exposure during pregnancy has shown elevated ASD risk in both groups (38). An additional method of accounting for confounding from genetic or environmental sources is discordant (on exposure) siblings analysis (61). It is important to acknowledge, however, that results of siblingcomparison studies may be biased if there are non-shared, time-varying confounders between siblings (62), as observed in one particular study (49). Negative control methods were utilized at two predominant levels: pre-conception use of SSRIs $(36,38)$ and paternal use of SSRIs $(40,63)$. Given the complicated use pattern of SSRIs and the variability of depressive states over time, these approaches may not be always valid (36).

In summary, of the empiric approaches to assessing the contribution of prenatal SSRIs exposure to ASD, none have been conclusively successful in teasing apart the role of maternal depression from that of medicinal treatment. The data are highly congruent, however, with one proposed biological mechanism of ASD development, serotonin metabolism dysfunctions, and serotonergic changes $(64,65)$. Along the described limitations in addressing indication bias, in utero SSRI exposure may potentially intervene with the end-point diagnosis as well (66). Mechanisms which impact adults' 5-HT can last after discontinuation of treatment, and can 


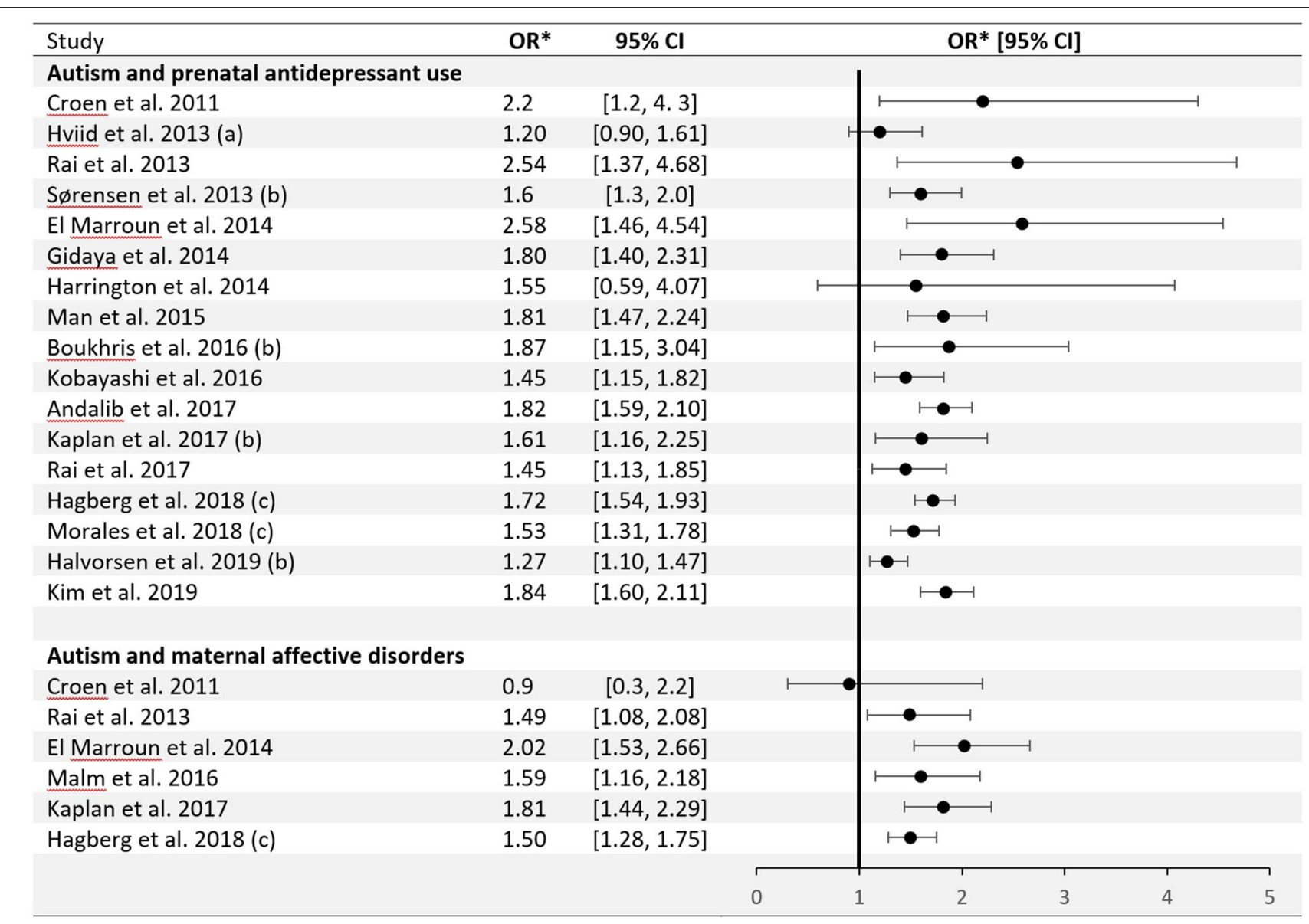

FIGURE 1 | Epidemiological studies of the association between autism and prenatal antidepressant use/maternal affective disorders: odds ratio ( \pm 95\% Confidence Interval). *Eight individual studies reported other outcome measures: (a) Rate Ratio; (b) Hazard Ratio; (c) Relative Risk.

potentiality alter affective and cognitive function in infants and children painting a specific clinical picture without necessarily causing autism.

\section{DISCUSSION}

It is plausible that we may soon be able to answer the question "can prenatal exposure to SSRIs cause ASD?" with a greater degree of certainty, yet the causal nature of this association does not address this public health topic in its entirety. First, the potential risks of exposure to SSRIs have to be evaluated while also considering the potential effects of untreated maternal depression on the fetus. An altered intrauterine environment due to maternal depression-related effects on hypothalamopituitary-adrenal (HPA) activity has been linked with adverse neurodevelopmental outcomes (10). Second, even if a scientific consensus is reached that SSRIs are detrimental to the fetus, it is unlikely that medications carry a constant risk throughout the entire pregnancy, and critical gestation periods during which the fetus is potentially more vulnerable should be identified. Some studies associated elevated ASD risk with first trimester SSRIs exposure $(34,38,67)$, while others linked adverse effects with SSRIs use in the second or third trimesters (45). Highlighting the above, a recent meta-analysis established that regardless of first trimester SSRI exposure, effects are also observed with second trimester exposure (40). Third, in the (currently hypothetical) case that a causal relationship is found, before considering amending the pregnancy safety category for SSRIs, it is recommended to have a sound estimation of the proportional ASD prevention that might be attributed to SSRI discontinuation, which as it currently stands appears to be very modest. It is estimated that between 0.6 and $2 \%$ of ASD cases in populationbased cohort studies could have been prevented if prenatal SSRIs exposure were eliminated $(36,48)$. These estimations refute suggestions that the trend of increasing ASD prevalence is attributable in a meaningful way to the increased use of $\mathrm{AD}$ medications. The perception by the individual pregnant woman of the potential risk associated with in-utero exposures is known to be perceived as greater than it actually is (68). Yet balanced public health policy and clinical decision-making regarding AD 
use during pregnancy would likely lead to better health outcomes for both mother and offspring.

In conclusion, there is little contention that SSRIs are associated with ASD. No study to date, however, has ruled out the possibility of confounding or by other factors indication in a convincing way. As accumulating data on this topic support that serotonin metabolism may be in the causal pathway to

\section{REFERENCES}

1. Hendrick V, Stowe ZN, Altshuler LL, Hwang S, Lee E, Haynes D. Placental passage of antidepressant medications. Am J Psychiatr. (2003) 160:993-6. doi: 10.1176/appi.ajp.160.5.993

2. Cooper WO, Willy ME, Pont SJ, Ray WA. Increasing use of antidepressants in pregnancy. Am J Obstet Gynecol. (2007) 196:544 e1-5. doi: 10.1016/j.ajog.2007.01.033

3. Jimenez-Solem E, Andersen JT, Petersen M, Broedbaek K, Andersen NL, Torp-Pedersen C, et al. Prevalence of antidepressant use during pregnancy in Denmark, a nation-wide cohort study. PLoS ONE. (2013) 8:e63034. doi: 10.1371/journal.pone.0063034

4. Margulis AV, Kang EM, Hammad TA. Patterns of prescription of antidepressants and antipsychotics across and within pregnancies in a population-based UK ohort. Matern Child Health J. (2014) 8:1742-52. doi: 10.1007/s10995-013-1419-2

5. Munk-Olsen T, Gasse C, Laursen TM. Prevalence of antidepressant use and contacts with psychiatrists and psychologists in pregnant and postpartum women. Acta Psychiatr Scand. (2012) 125:318-24. doi: 10.1111/j.1600-0447.2011.01784.x

6. Freeman MP. Antidepressant medication treatment during pregnancy: prevalence of use, clinical implications, and alternatives. J Clin Psychiatr. (2011) 72:977-8. doi: 10.4088/JCP.11f07206

7. Andrade SE, Raebel MA, Brown J, Lane K, Livingston J, Boudreau D, et al. Use of antidepressant medications during pregnancy: a multisite study. Am J Obstet Gynecol. (2008) 198:194. e1-5. doi: 10.1016/j.ajog.2007.07.036

8. Olfson M, Marcus SC. National patterns in antidepressant medication treatment. Arch Gen Psych. (2009) 66:848-56. doi: 10.1001/archgenpsychiatry.2009.81

9. Dunkel Schetter C. Psychological science on pregnancy: stress processes, biopsychosocial models, and emerging research issues. Ann Rev Psychol. (2011) 62:531-58. doi: 10.1146/annurev.psych.031809.130727

10. Martin RP, Dombrowski, Stefan C. Prenatal Exposures: Psychological and Educational Consequences for Children. New York, NY: Springer (2008).

11. Rice F, Jones I, Thapar A. The impact of gestational stress and prenatal growth on emotional problems in offspring: a review. Acta Psychiatr Scand. (2007) 3:171-83. doi: 10.1111/j.1600-0447.2006.00895.x

12. Blumberg SJ, Bramlett MD, Kogan MD, Schieve LA, Jones JR, Lu MC. Changes in prevalence of parent-reported autism spectrum disorder in school-aged US children: 2007 to 2011-2012. Natl Health Stat Rep. (2013) 20:1-11.

13. Fombonne E. Epidemiology of pervasive developmental disorders. Pediatr Res. (2009) 65:591-8. doi: 10.1203/PDR.0b013e31819e7203

14. Bailey A, Le Couteur A, Gottesman I, Bolton P, Simonoff E, Yuzda E, et al. Autism as a strongly genetic disorder: evidence from a British twin study. Psychol Med. (1995) 25:63-77. doi: 10.1017/S0033291700028099

15. Smalley SL, Asarnow RF, Spence MA. Autism and genetics: a decade of research. Arch Gen Psychiatr. (1988) 45:953-61. doi: 10.1001/archpsyc.1988.01800340081013

16. Bristol MM, Cohen DJ, Costello EJ, Denckla M, Eckberg TJ, Kallen R, et al. State of the science in autism: report to the national institutes health. J Autism Dev Disord. (1996) 26:121-54. doi: 10.1007/BF02172002

17. Trowbridge S, Narboux-Neme N, Gaspar P. Genetic models of serotonin (5-HT) depletion: what do they tell us about the developmental role of 5-HT? Anatomical Record. (2011) 294:1615-23. doi: 10.1002/ar.21248

18. Narboux-Neme N, Pavone LM, Avallone L, Zhuang X, Gaspar P. Serotonin transporter transgenic (SERTcre) mouse line reveals developmental targets of serotonin specific reuptake inhibitors (SSRIs). Neuropharmacology. (2008) 55:994-1005. doi: 10.1016/j.neuropharm.2008.08.020
ASD, there is need for novel approaches that could elucidate this conundrum (69).

\section{AUTHOR CONTRIBUTIONS}

OK and RG conceived the work and drafted the article. RR provided critical suggestions for revisions.

19. Gaspar P, Cases O, Maroteaux L. The developmental role of serotonin: news from mouse molecular genetics. Nat Rev Neurosci. (2003) 4:1002-12. doi: $10.1038 /$ nrn1256

20. Vitalis T, Cases O, Passemard S, Callebert J, Parnavelas JG. Embryonic depletion of serotonin affects cortical development. Eur J Neurosci. (2007) 26:331-44. doi: 10.1111/j.1460-9568.2007.05661.x

21. Vitalis T, Parnavelas JG. The role of serotonin in early cortical development. Develop Neurosci. (2003) 25:245-56. doi: 10.1159/000072272

22. Cases O, Vitalis T, Seif I, De Maeyer E, Sotelo C, Gaspar P. Lack of barrels in the somatosensory cortex of monoamine oxidase A-deficient mice: role of a serotonin excess during the critical period. Neuron. (1996) 16:297-307. doi: 10.1016/S0896-6273(00)80048-3

23. El Marroun H, Jaddoe VW, Hudziak JJ, Roza SJ, Steegers EA, Hofman A, et al. Maternal use of selective serotonin reuptake inhibitors, fetal growth, and risk of adverse birth outcomes. Arch Gen Psychiatr. (2012) 69:706-14. doi: 10.1001/archgenpsychiatry.2011.2333

24. Chambers CD, Johnson KA, Dick LM, Felix RJ, Jones KL. Birth outcomes in pregnant women taking fluoxetine. N Eng J Med. (1996) 335:1010-5. doi: 10.1056/NEJM199610033351402

25. Alwan S, Reefhuis J, Rasmussen SA, Olney RS, Friedman JM, National Birth Defects Prevention S. Use of selective serotonin-reuptake inhibitors in pregnancy and the risk of birth defects. N Eng J Med. (2007) 356:2684-92. doi: 10.1056/NEJMoa066584

26. Malm H, Artama M, Gissler M, Ritvanen A. Selective serotonin reuptake inhibitors and risk for major congenital anomalies. Obst Gynecol. (2011) 118:111-20. doi: 10.1097/AOG.0b013e318220edcc

27. Berard A, Zhao JP, Sheehy O. Antidepressant use during pregnancy and the risk of major congenital malformations in a cohort of depressed pregnant women: an updated analysis of the Quebec Pregnancy Cohort. BMJ Open. (2017) 7:e013372. doi: 10.1136/bmjopen-2016-013372

28. Berard A, Zhao JP, Sheehy O. Sertraline use during pregnancy and the risk of major malformations. Am J Obstet Gynecol. (2015) 212:795e1-12. doi: 10.1016/j.ajog.2015.01.034

29. Berard A, Sheehy O, Zhao JP, Vinet E, Bernatsky S, Abrahamowicz M. SSRI and SNRI use during pregnancy and the risk of persistent pulmonary hypertension of the newborn. Br J Clin Pharmacol. (2017) 83:1126-33. doi: $10.1111 /$ bcp. 13194

30. Kieler H, Artama M, Engeland A, Ericsson O, Furu K, Gissler M, et al. Selective serotonin reuptake inhibitors during pregnancy and risk of persistent pulmonary hypertension in the newborn: population based cohort study from the five Nordic countries. BMJ. (2012) 344:d8012. doi: 10.1136/bmj.d8012

31. Jensen HM, Gron R, Lidegaard O, Pedersen LH, Andersen PK, Kessing LV. Maternal depression, antidepressant use in pregnancy and Apgar scores in infants. Br J Psychiatr. (2013) 202:347-51. doi: 10.1192/bjp.bp.112.115931

32. Andalib S, Emamhadi MR, Yousefzadeh-Chabok S, Shakouri SK, HøilundCarlsen PF, et al. Maternal SSRI exposure increases the risk of autistic offspring: a meta-analysis and systematic review. Eur Psychiatr. (2017) 45:161-6. doi: 10.1016/j.eurpsy.2017.06.001

33. Boukhris T, Sheehy O, Mottron L, Bérard A. Antidepressant use during pregnancy and the risk of autism spectrum disorder in children. JAMA Pediatr. (2016) 170:117-24. doi: 10.1001/jamapediatrics.2015.3356

34. Croen LA, Grether JK, Yoshida, CK, Odouli R, Hendrick V. Antidepressant use during pregnancy and childhood autism spectrum disorders. Arch Gen Psychiatr. (2011) 68:1104-12. doi: 10.1001/archgenpsychiatry.2011.73

35. El Marroun TJ, White NJ, Homberg G, Schoemaker NK, Jaddoe VW, Hofman A, et al. Prenatal exposure to selective serotonin reuptake inhibitors and social responsiveness symptoms of autism: population-based study of young children. Br J Psychiatr. (2014) 205:95-102. doi: 10.1192/bjp.bp.113.127746 
36. Gidaya NB, Lee BK, Burstyn I, Yudell M, Mortensen EL, Newschaffer CJ. In utero exposure to selective serotonin reuptake inhibitors and risk for autism spectrum disorder. J Autism Develop Dis. (2014) 44:2558-67. doi: 10.1007/s10803-014-2128-4

37. Hagberg KW, Robijn AL, Jick S. Maternal depression and antidepressant use during pregnancy and the risk of autism spectrum disorder in offspring. Clin Epidemiol. (2018) 10:1599-612. doi: 10.2147/CLEP.S180618

38. Kaplan YC, Keskin-Arslan E, Acar S, Sozmen K. Maternal SSRI discontinuation, use, psychiatric disorder and the risk of autism in children: a meta-analysis of cohort studies. Br J Clin Pharmacol. (2017) 83:2798-806. doi: $10.1111 /$ bcp. 13382

39. Kobayashi T, Matsuyama T, Takeuchi M, Ito S. Autism spectrum disorder and prenatal exposure to selective serotonin reuptake inhibitors: A systematic review and meta-analysis. Reproduct Toxicol. (2016) 65:170-8. doi: 10.1016/j.reprotox.2016.07.016

40. Halvorsen A, Hesel B, Østergaard SD, Danielsen AA. In utero exposure to selective serotonin reuptake inhibitors and development of mental disorders: a systematic review and meta-analysis. Acta Psychiatr Scand. (2019) 139:493507. doi: 10.1111/acps.13030

41. Harrington RA, Lee LC, Crum RM, Zimmerman AW, HertzPicciotto I. Prenatal SSRI use and offspring with autism spectrum disorder or developmental delay. Pediatrics. (2014) 133:e1241-8. doi: 10.1542/peds.2013-3406

42. Hviid A, Melbye M, Pasternak B. Use of selective serotonin reuptake inhibitors during pregnancy and risk of autism. N Eng J Med. (2013) 359:2406-15. doi: 10.1056/NEJMoa1301449

43. Kim JY, Son MJ, Son CY, Radua J, Eisenhut M, Gressier F, et al. Environmental risk factors and biomarkers for autism spectrum disorder: an umbrella review of the evidence. Lancet Psychiatr. (2019) 6:590-600. doi: 10.1016/S2215-0366(19)30181-6

44. Malm H, Brown AS, Gissler M, Gyllenberg D, Hinkka-Yli-Salomäki S, McKeague IW, et al. Gestational exposure to selective serotonin reuptake inhibitors and offspring psychiatric disorders: a national register-based study. J Am Acad Child Adolesc. (2016) 55:359-66. doi: 10.1016/j.jaac.2016.02.013

45. Man KK, Tong HH, Wong LY, Chan EW, Simonoff E, Wong IC. Exposure to selective serotonin reuptake inhibitors during pregnancy and risk of autism spectrum disorder in children: a systematic review and metaanalysis of observational studies. Neurosci Biobehav Rev. (2015) 49:82-9. doi: 10.1016/j.neubiorev.2014.11.020

46. Morales D, Slattery J, Evans S, Kurz X. Antidepressant use during pregnancy and risk of autism spectrum disorder and attention deficit hyperactivity disorder: systematic review of observational studies and methodological considerations. BMC Med. (2018) 16:6. doi: 10.1186/s12916-017-0993-3

47. Rai D, Lee BK, Dalman C, Golding J, Lewis G, Magnusson C. Parental depression, maternal antidepressant use during pregnancy, and risk of autism spectrum disorders: population based case-control study. BMJ. (2013) 346:f2059. doi: 10.1136/bmj.f2059

48. Rai D, Lee BK, Dalman C, Newschaffer C, Lewis G, Magnusson C. Antidepressants during pregnancy and autism in offspring: population based cohort study. BMJ. (2017) 358:j2811. doi: 10.1136/bmj.j2811

49. Sørensen MJ, Grønborg TK, Christensen J, Parner ET, Vestergaard M, Schendel D, et al. Antidepressant exposure in pregnancy and risk of autism spectrum disorders. Clin Epidemiol. (2013) 5:449-59. doi: 10.2147/CLEP.S53009

50. Zhou XH, Li YJ, Ou JJ, Li YM. Association between maternal antidepressant use during pregnancy and autism spectrum disorder: an updated metaanalysis. Mol Autism. (2018) 9:21. doi: 10.1186/s13229-018-0207-7

51. Glover ME, Clinton SM. Of rodents and humans: A comparative review of the neurobehavioral effects of early life SSRI exposure in preclinical and clinical research. Int J Dev Neurosci. (2016) 51:50-72. doi: 10.1016/j.ijdevneu.2016.04.008

52. Maciag D, Simpson KL, Coppinger D, Lu Y, Wang Y, Lin RC, et al. Neonatal antidepressant exposure has lasting effects on behavior and serotonin circuitry. Neuropsychopharma. (2006) 31:47. doi: 10.1038/sj.npp.1300823

53. Glover ME, Pugh PC, Jackson NL, Cohen JL, Fant AD, Akil H, et al. Early-life exposure to the SSRI paroxetine exacerbates depression-like behavior in anxiety/depression-prone rats. Neuroscience. (2015) 284:775-97. doi: 10.1016/j.neuroscience.2014.10.044
54. Sprowles JL, Hufgard JR, Gutierrez A, Bailey RA, Jablonski SA, Williams MT, et al. Perinatal exposure to the selective serotonin reuptake inhibitor citalopram alters spatial learning and memory, anxiety, depression, and startle in Sprague-Dawley rats. Int J Develop Neurosci. (2016) 54:39-52. doi: 10.1016/j.ijdevneu.2016.08.007

55. Vorhees CV, Acuff-Smith KD, Schilling MA, Fisher JE, Moran MS, Buelke-Sam J. A developmental neurotoxicity evaluation of the effects of prenatal exposure to fluoxetine in rats. Toxicolog Sci. (1994) 23:194-205. doi: 10.1093/toxsci/23.2.194

56. Evans J, Heron J, Francomb H, Oke S, Golding J. Cohort study of depressed mood during pregnancy and after childbirth. BMJ. (2001) 323:257-60. doi: 10.1136/bmj.323.7307.257

57. Jimenez-Solem E, Andersen JT, Petersen P, Broedbaek K, Jensen JK, Afzal $\mathrm{S}$, et al. Exposure to selective serotonin reuptake inhibitors and the risk of congenital malformations: A nationwide cohort study. BMJ Open. (2012) 2:1-9. doi: 10.1136/bmjopen-2012-001148

58. Josefsson A, Berg G, Nordin C, Sydsjo G. Prevalence of depressive symptoms in late pregnancy and postpartum. Acta Obst Gynecol Scand. (2001) 80:251-5. doi: 10.1034/j.1600-0412.2001.080003251.x

59. Lund N, Pedersen LH, Henriksen TB. Selective serotonin reuptake inhibitor exposure in utero and pregnancy outcomes. Arch Pediatr Adolescent Med. (2009) 163:949-54. doi: 10.1001/archpediatrics.2009.164

60. Olesen C, Thrane N, Nielsen GL, Sorensen HT, Olsen J. A population-based prescription study of asthma drugs during pregnancy: Changing the intensity of asthma therapy and perinatal outcomes. Respiration. (2001) 68:256-61. doi: 10.1159/000050507

61. Susser E, Eide MG, Begg M. Invited commentary: The use of sibship studies to detect familial confounding. Am J Epidemiol. (2010) 172:537-9. doi: 10.1093/aje/kwq196

62. Frisell T, Oberg S, Kuja-Halkola R, Sjolander, A. Sibling comparison designs: bias from non-shared confounders and measurement error. Epidemiology. (2012) 23:713-20. doi: 10.1097/EDE.0b013e31825fa230

63. Viktorin A, Levine SZ, Altemus M, Reichenberg A., Sandin S. Paternal use of antidepressants and offspring outcomes in Sweden: nationwide prospective cohort study. BMJ. (2018) 361:k2233. doi: 10.1136/bmj.k2233

64. Anderson GM, Czarkowski K, Ravski N, Epperson CN. Platelet serotonin in newborns and infants: ontogeny, heritability, and effect of in utero exposure to selective serotonin reuptake inhibitors. Pediatric Res. (2004) 56:418. doi: 10.1203/01.PDR.0000136278.23672.A0

65. Cook EH, Leventhal BL, Freedman DX. Free serotonin in plasma: autistic children and their first-degree relatives. Biol Psychiat. (1988) 24:488-91. doi: 10.1016/0006-3223(88)90192-8

66. Fatima Z, Zahra A, Ghouse M, Wang X, Yuan Z. Maternal SSRIs experience and risk of ASD in offspring: a review. Toxicol Res. (2018) 7:1020-8. doi: 10.1039/C8TX00102B

67. Reefhuis J, Devine O, Friedman JM, Louik C, Honein MA. Specific SSRIs and birth defects: Bayesian analysis to interpret new data in the context of previous reports. BMJ. (2015) 351:h3190. doi: 10.1136/bmj.h3190

68. Petersen I, McCrea RL, Lupattelli A, Nordeng H. Women's perception of risks of adverse fetal pregnancy outcomes: a large-scale multinational survey. BMJ Open. (2015) 5:e007390. doi: 10.1136/bmjopen-2014-007390

69. Sujan AC, Oberg S, Quinn PD, D’Onofrio BM. Annual research review: maternal antidepressant use during pregnancy and offspring neurodevelopmental problems - a critical review and recommendation for future research. J Child Psychol Psychiatr. (2019) 60:356-76. doi: $10.1111 /$ jcpp.13004

Conflict of Interest: The authors declare that the research was conducted in the absence of any commercial or financial relationships that could be construed as a potential conflict of interest.

Copyright (C) 2020 Kapra, Rotem and Gross. This is an open-access article distributed under the terms of the Creative Commons Attribution License (CC BY). The use, distribution or reproduction in other forums is permitted, provided the original author(s) and the copyright owner(s) are credited and that the original publication in this journal is cited, in accordance with accepted academic practice. No use, distribution or reproduction is permitted which does not comply with these terms. 